\title{
Desempenho e Morfometria da Mucosa de Duodeno de Frangos de Corte Alimentados com Farelo de Canola, Durante o Período Inicial ${ }^{1}$
}

\author{
Denise Fontana Figueiredo ${ }^{2}$, Alice Eiko Murakami ${ }^{3}$, Marli Aparecida dos Santos Pereira ${ }^{4}$, \\ Antonio Claudio Furlan ${ }^{3}$, Fábio Luiz Buranelo Toral ${ }^{2}$
}

\begin{abstract}
RESUMO - Um experimento foi conduzido para verificar o efeito da utilização de níveis crescentes (0, 10, 20, 30 e 40\%) de farelo de canola nas rações de frangos de corte, sobre o desempenho e a morfologia da mucosa, durante o período inicial (1 - 21 dias) e os efeitos de sua utilização no período de crescimento. Foram utilizados 1000 pintos machos de um dia de idade, distribuídos em delineamento experimental inteiramente casualizado, com cinco tratamentos, quatro repetições e 50 aves por unidade experimental. No $1^{\underline{0}}$, 21으 e $41^{\underline{0}}$ dia, as aves e as rações foram pesadas e no 21 o dia duas aves de cada unidade experimental foram sacrificadas para a colheita de um segmento do duodeno para avaliação de morfometria intestinal. Os resultados demonstraram que níveis crescentes de farelo de canola induziram à redução linear no ganho de peso, peso médio e consumo de ração e piora na conversão alimentar. Durante o período de crescimento (21 a 41 dias), no qual todas as aves receberam ração semelhante, observou-se decréscimo no peso médio e ganho de peso, com o aumento dos níveis de farelo de canola, enquanto os parâmetros conversão alimentar e consumo de ração foram semelhantes. Os dados referentes a morfometria da mucosa intestinal, submetidos à análise de regressão, demonstraram que houve aumento na profundidade de cripta conforme o aumento nos níveis de farelo de canola. Os resultados permitem afirmar que é possível a inclusão de até $20 \%$ de farelo de canola, sem prejuízos no desempenho das aves e no trato digestório.
\end{abstract}

Palavras-chave: altura de vilo, duodeno, fator antinutricional, profundidade de cripta, tanino

\section{Performance and Duodenum Mucous Morphometry of Broiler Chickens Fed Canola Meal, During the Starting Period}

\begin{abstract}
A trial was carried to verify the effect of increasing levels (0, 10, 20, 30 and 40\%) of canola meal in diets of broiler chickens, on performance and mucous morphology, during the starting period ( 1 - 21 days). 1,000 male chicks one-day-old were used, distributed in a randomized experimental assay, with five treatments, four replicates and 50 birds per experimental unit. At the $1^{\text {st }}, 21^{\text {st }}$ and $41^{\text {st }}$ days, the birds and the rations were weighed and at the $21^{\text {st }}$ day two birds of each experimental unit were sacrificed for collection of a duodenum segment for evaluation of intestinal morphometry. The results demonstrated that increasing levels of canola meal induced to a linear reduction in weight gain, weight and feed intake and worst feed conversion. During the growing period (21 to 41 days), in which all of the birds received similar diet, a decrease was observed in the weight and weight gain, with the increase of the levels of canola meal, while parameters feed conversion and feed intake were similar. Data regarding mucous morphology, submitted to the regression analysis, demonstrated that there was increase in crypt depth in accordance of increasing levels of canola meal. It is possible to include up to $20 \%$ of canola meal without damages on broiler performance and in the digestive tract.
\end{abstract}

Key Words: villi height, duodenum, anti-nutritional factor, crypt depth, tannin

\section{Introdução}

Aproximadamente $70 \%$ do custo de produção de frangos de corte deve-se à alimentação, sendo a fonte protéica o que mais encarece a ração. Desta forma, é de suma importância a elaboração de rações mais eficientes e econômicas e, para isso, a utilização de alimentos não convencionais, disponíveis regional- mente precisam ser melhor avaliados. Nessas avaliações, devem ser considerados o valor nutritivo do alimento, o melhor nível de sua inclusão nas rações e sua viabilidade econômica (Nascimento, 1997).

No Brasil, as rações para aves têm como fonte protéica básica o farelo de soja. O farelo de canola, um dos ingredientes que vem sendo testado como alternativa para substituir, em parte ou no todo, o

${ }^{1}$ Trabalho apresentado ao Departamento de Zootecnia da Universidade Estadual de Maringá como parte das exigências para obtenção do título de Zootecnista.

${ }^{2}$ Zootecnistas, alunos do Programa de Pós-Graduação em Zootecnia da FCAV/UNESP, Rod. Paulo Donato Castellane, Km 5, S/N, CEP: 14870-000, Jaboticabal - SP. E.mail: deniseffigueiredo@yahoo.com.br; flbtoral@hotmail.com

3 Professores do Departamento de Zootecnia da UEM, Av. Colombo 5790, CEP: 87020-900, Maringá - PR. E.mail: aemurakami@uem.br; acfurlan@uem.br

4 Professora do Departamento de Ciências Morfofisiológicas da UEM. E.mail: madspereira@uem.br 
farelo de soja nas rações, é um subproduto da extração do óleo comestível, cuja composição é indicadora de seu potencial para utilização como fonte protéica em rações para animais (Franzoi et al., 2000).

A canola é uma cultura alternativa de inverno, que se adequa bem às nossas condições climáticas e foi desenvolvida a partir do melhoramento da colza (B. campestris e B. napus), constituindo-se em uma fonte protéica promissora (Nerilo, 1995), sendo primariamente utilizada para produção de óleo para consumo humano. Estima-se que a produção mundial anual desta leguminosa seja de 33,6 milhões de toneladas, conseqüentemente, consideráveis quantidades de farelo de canola (17,7 milhões de toneladas) estão disponíveis para o uso na produção animal (Kocher et al., 2000).

$\mathrm{O}$ empenho de pesquisadores vem garantindo melhorias cada vez mais expressivas na produtividade e no valor nutritivo da cultura, com redução dos níveis de glucosinolato, o qual é responsável pela redução na eficiência alimentar e ganho de peso, melhora na palatabilidade do farelo, diminuição dos níveis de fibra bruta e conseqüente aumento do nível de proteína (Murakami et al., 1995a).

As primeiras variedades de colza continham níveis altos de fatores antinutricionais (FANs), principalmente de ácido erúcico e glucosinolatos (Nascimento, 1997). Os glucosinolatos, quando intactos, não são tóxicos, mas os produtos de sua hidrólise, pela ação da enzima mirosinase, o são. Esta enzima está presente junto aos glucosinolatos alifáticos, cujo precursor é a metionina, nas sementes de canola; a separação física durante o processamento comercial produz a degradação dos glucosinolatos, liberando glicose, isotiocianetos, nitrilos e gointrinas, que podem interferir no tamanho, na estrutura e na função da glândula tireóide, inibindo a síntese e secreção dos hormônios tireoidianos, resultando em redução da eficiência alimentar e ganho de peso. No entanto, estudos conflitantes afirmam que a absorção de glucosinolatos intactos podem causar efeitos antinutricionais tanto quanto os produtos de sua hidrólise (Bell, 1993).

As novas variedades, denominadas de canola (Canadian Oil Low Acid), apresentam menores níveis de glucosinolatos, ácido erúcico e fibra bruta (Nascimento, 1997), no entanto, apresentam níveis elevados de tanino em sua composição.

Os taninos são FANs encontrados em diversos alimentos, variando entre 1,6 e 3,0\% no farelo de canola. Na semente de canola, estão presentes, principalmente na casca, ocorrendo com mais freqüência nas escuras que na amarelas (Bell, 1993). São metabólitos fenólicos solúveis em água, de origem vegetal, com peso molecular de 500 Daltons ou mais e têm a habilidade de se ligar ou precipitar proteínas de soluções aquosas. Os taninos existem nas formas hidrolisáveis ou condensadas e não se conhece a sua função no crescimento ou reprodução da planta, mas suspeita-se que desempenhe algum papel na prevenção ao ataque de aves, pestes e fungos (Jansman, 1993).

Os taninos causam efeitos deletérios, como redução na ingestão de alimentos, fato atribuído ao sabor adstringente que exercem pela combinação com as proteínas salivares e muco do epitélio da cavidade oral, menor eficiência alimentar, redução na digestibilidade dos nutrientes, inibição das enzimas digestivas (Pour-Reza \& Edriss, 1997) e aumento na incidência de discondroplasia tibial em frangos (Nyachoti et al., 1997).

Há ainda dois tipos de compostos que podem influenciar no valor nutricional do farelo de canola, a sinapina e o ácido fítico; estes, juntamente com o tanino podem alcançar valores superiores a $10 \%$ da composição total do farelo. A sinapina (0,6 a 1,8\%) possui sabor amargo, afetando o consumo de ração e o ácido fítico (3 a 6\%) reduz a absorção de minerais como Mg, Ca, Mn, Zn e Cu (Bell, 1993).

Franzoi et al. (1998) observaram redução linear no consumo de ração e ganho de peso de frangos de corte, havendo, no entanto, melhora na conversão alimentar para os maiores níveis de inclusão de canola. Kocher et al. (2000) verificaram menor consumo de ração, ganho de peso e pior conversão alimentar para as aves alimentadas com farelo de canola dos 7 aos 28 dias de idade.

Nascimento (1997), utilizando níveis de inclusão de farelo de canola até $40 \%$, relata que houve maior ganho de peso e consumo de ração para as aves alimentadas com níveis inferiores; no entanto, não houve diferença para a variável conversão alimentar. O autor justifica ainda que os baixos valores de ganho de peso podem ser em virtude do alto teor de fibra bruta encontrado no farelo de canola, que induziria a redução na digestibilidade dos nutrientes, principalmente da proteína ou ao menor consumo de ração.

Murakami et al. (1995b) relataram maior ganho de peso e melhor conversão alimentar para inclusão de níveis máximos de $15 \%$ de farelo de canola, não tendo sido observadas diferenças no consumo de 
ração para o período inicial. Leeson et al. (1978) não observaram diferenças no ganho de peso para frangos de corte alimentados com sementes inteiras de colza incluídas à ração em níveis inferiores a 20\% até quatro semanas de idade, no entanto, observaram ligeiro decréscimo na conversão alimentar durante este período inicial.

Ao testar o uso de casca de canola de duas variedades em níveis de 10 e $20 \%$ para aves de 0 a 3 semanas, Mitaru et al. (1983) obtiveram valores médios de ganho de peso, consumo e eficiência alimentar superiores quando comparados com a ração a base de casca de soja. Paralelamente a este experimento, os autores relatam um ligeiro aumento nos parâmetros supracitados quando da utilização de farelo de canola a $20 \%$, casca de canola a $5 \%$ e extrato de casca de canola a 5 e 10\%, em comparação à utilização de ração a base de farelo de soja.

No entanto, Leeson et al. (1987), utilizando farelo de canola, relataram não haver efeito na substituição de até $100 \%$ do farelo de soja pelo de canola no consumo de ração, ganho de peso e conversão alimentar.

Portanto, o objetivo do presente trabalho foi verificar o efeito da utilização de níveis crescentes $(0,10$, 20, 30 e 40\%) de farelo de canola nas rações de frangos de corte, sobre a morfologia da mucosa duodenal e o desempenho durante o período inicial (1 - 21 dias), bem como o reflexo no desempenho das aves no período de crescimento (22 - 41 dias).

\section{Material e Métodos}

O experimento foi realizado no Aviário Experimental da Fazenda Experimental de Iguatemi, da Universidade Estadual de Maringá - Maringá, Paraná, no período de 6 de março a 16 de abril de 2001. Foram utilizados 1000 pintos de um dia, machos, da marca comercial Cobb, alojados em galpão convencional $30 \times 8 \mathrm{~m}$, dividido em boxes de $5,1 \mathrm{~m}^{2}$, forrados com cama tipo maravalha, com cobertura de telha francesa e lanternim, piso de concreto e paredes laterais de alvenaria com 0,40 m de altura, completadas com tela de arame até o telhado. A temperatura durante o período experimental foi obtida às 8 e $14 \mathrm{~h}$, sendo as médias de máxima, mínima, bulbo seco e bulbo úmido de 29,38 $\pm 2,54,22,28 \pm 2,40,24,55 \pm 3,54$ e $21,28 \pm 2,05^{\circ} \mathrm{C}$, respectivamente e a umidade de $74,53 \pm 14,69 \%$.

As aves foram distribuídas em um delineamento experimental inteiramente casualizado, com cinco tratamentos e quatro repetições, com 50 aves por unidade experimental.

As rações foram formuladas com dados de composição química e valores energéticos dos alimentos de acordo com Rostagno et al (2000) e com as exigências da marca comercial para o período inicial ( 1 a 21 dias) e de crescimento (22 a 41 dias), de forma que fossem isoprotéicas, isocalóricas, isoaminoacídicas para met+cis e lis, isocálcicas e isofosfóricas (Tabela 1). No período inicial foram fornecidas cinco rações (testemunha e 10, 20, 30 e 40\% de inclusão de farelo de canola) e no período de crescimento foi fornecida uma única ração a base de milho e farelo de soja, a fim de verificar as conseqüências da utilização do farelo de canola no período inicial sobre o desempenho das aves aos 41 dias.

O farelo de canola utilizado apresentou em sua composição química 38,49\% de proteína bruta (PB), $15,52 \%$ de fibra bruta (FB), 6,34\% de matéria mineral, $260 \mathrm{mg} / \mathrm{kg}$ de cloretos totais, 161,4 mg/kg de sódio e 2,16\% de tanino, conforme análises realizadas pelo Laboratório de Alta Tecnologia - LAB TEC - de Campinas. Durante o experimento, as aves receberam água e ração ad libitum, sendo as rações pesadas no início e no fim de cada fase para controle de consumo e de conversão alimentar.

No $1^{\underline{0}}, 21^{\underline{0}}$ e $41^{\underline{0}}$ dia, as aves e as rações foram pesadas e no $21^{\circ}$ dia de experimento foi retirada uma amostra aleatória de duas aves de cada repetição, as quais foram pesadas e abatidas por decapitação, para escoamento do sangue. Procedeu-se à colheita de uma porção do duodeno de aproximadamente $4 \mathrm{~cm}$, a qual foi fixada por imersão em solução de Bouin. Os fragmentos dos tecidos foram destinados à rotina histológica com inclusão do material em parafina. Após a microtomia, foram obtidos 15 cortes longitudinais e semi-seriados de $5 \mu \mathrm{m}$ de espessura, corados pela técnica do Ácido Periódico de Schiff (PAS) e Hematoxilina. As análises histológicas de morfometria foram realizadas no Departamento de Ciências Morfofisiológicas; a captura de imagens foi feita através de câmera digital de alta resolução PRO SERIES da Media Cibertecnics, acoplada ao microscópio Olimpus Bx 40. Para leitura das imagens foi utilizado o programa IMAGE PROPLUS 4.1, da Media Cibertecnics. Foram avaliadas altura de vilo, profundidade de cripta e relação vilo:cripta.

Os dados foram analisados de acordo com o seguinte modelo estatístico:

$$
Y_{i j}=\mu+N_{i}+e_{i j} \text {, }
$$


Tabela 1 - Composição percentual e química das rações experimentais

Table 1 - Percentual and chemical composition of the experimental diets

\begin{tabular}{|c|c|c|c|c|c|c|}
\hline \multirow[b]{3}{*}{$\begin{array}{l}\text { Ingredientes } \\
\text { Ingredients }\end{array}$} & \multicolumn{5}{|c|}{ 1-21 dias } & \multirow{3}{*}{$\begin{array}{c}22-41 \text { dias } \\
0 \%\end{array}$} \\
\hline & \multicolumn{5}{|c|}{$\begin{array}{c}\text { Farelo de canola } \\
\text { Canola meal }\end{array}$} & \\
\hline & $0 \%$ & $10 \%$ & $20 \%$ & $30 \%$ & $40 \%$ & \\
\hline $\begin{array}{l}\text { Milho } \\
\text { Corn }\end{array}$ & 58,06 & 54,82 & 51,58 & 48,34 & 45,10 & 63,35 \\
\hline $\begin{array}{l}\text { Farelo de soja } \\
\text { Soybean meal }\end{array}$ & 35,83 & 28,39 & 20,95 & 13,52 & 6,08 & 31,41 \\
\hline $\begin{array}{l}\text { Farelo de canola } \\
\text { Canola meal }\end{array}$ & - & 10,00 & 20,00 & 30,00 & 40,00 & - \\
\hline $\begin{array}{l}\text { Óleo vegetal } \\
\text { Vegetal oil }\end{array}$ & 2,42 & 3,30 & 4,18 & 5,05 & 5,93 & 1,84 \\
\hline $\begin{array}{l}\text { Fosfato bicálcico } \\
\text { Dicalcium phosphate }\end{array}$ & 1,78 & 1,69 & 1,59 & 1,49 & 1,39 & 1,59 \\
\hline $\begin{array}{l}\text { Calcário } \\
\text { Limestone }\end{array}$ & 1,00 & 0,98 & 0,95 & 0,93 & 0,90 & 0,93 \\
\hline $\begin{array}{l}\text { Sal } \\
\text { Salt }\end{array}$ & 0,30 & 0,30 & 0,30 & 0,30 & 0,30 & 0,26 \\
\hline $\begin{array}{l}\text { DL-Metionina 99\% } \\
\text { D-Methionine }\end{array}$ & 0,23 & 0,17 & 0,13 & 0,06 & - & 0,23 \\
\hline $\begin{array}{l}\text { L-Lisina HCl } \\
\text { L-Lysine } \mathrm{HCl}\end{array}$ & 0,15 & 0,14 & 0,13 & 0,11 & 0,10 & 0,18 \\
\hline $\begin{array}{l}\text { Suplemento mineral } \\
\text { Mineral supplement }\end{array}$ & 0,10 & 0,10 & 0,10 & 0,10 & 0,10 & 0,10 \\
\hline $\begin{array}{l}\text { Suplemento vitamínico }{ }^{2} \\
\text { Vitaminic suplement }\end{array}$ & 0,10 & 0,10 & 0,10 & 0,10 & 0,10 & 0,10 \\
\hline $\begin{array}{l}\text { BHT }^{3} \\
\text { Antioxidant }\end{array}$ & 0,01 & 0,01 & 0,01 & 0,01 & 0,01 & 0,01 \\
\hline $\begin{array}{l}\text { TOTAL } \\
\text { Total } \\
\text { Composição calculada }\end{array}$ & 100,00 & 100,00 & 100,00 & 100,00 & 100,00 & 100,00 \\
\hline $\begin{array}{l}\text { Calculated composition } \\
\text { Proteína bruta }(\%) \\
\text { Crude protein }\end{array}$ & 21,54 & 21,54 & 21,54 & 21,54 & 21,54 & 20,00 \\
\hline $\begin{array}{l}\text { Energia metabolizável (kcal/kg) } \\
\text { Metabolizable energy }\end{array}$ & 3.000 & 3.000 & 3.000 & 3.000 & 3.000 & 3.150 \\
\hline $\begin{array}{l}\text { Lisina (\%) } \\
\text { Lysine }\end{array}$ & 1,26 & 1,26 & 1,26 & 1,26 & 1,26 & 1,17 \\
\hline $\begin{array}{l}\text { Metionina + Cistina (\%) } \\
\text { Methyonine + Cystine }\end{array}$ & 0,90 & 0,90 & 0,90 & 0,90 & 0,90 & 0,86 \\
\hline $\begin{array}{l}\text { Cálcio (\%) } \\
\text { Calcium }\end{array}$ & 0,96 & 0,96 & 0,96 & 0,96 & 0,96 & 0,87 \\
\hline $\begin{array}{l}\text { Fósforo disponível (\%) } \\
\text { Available phosphorus }\end{array}$ & 0,45 & 0,45 & 0,45 & 0,45 & 0,45 & 0,41 \\
\hline 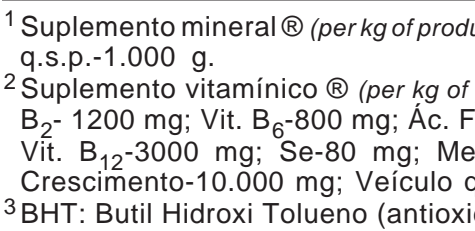 & e-100. & $\begin{array}{l}\text { n-16.00 } \\
\text { oo UI; } \\
\text { tínico- }\end{array}$ & $\begin{array}{l}100.000 \\
.000 \mathrm{U} \\
\text { Biotina- }\end{array}$ & $\begin{array}{l}.000 \mathrm{~ms} \\
\text { Do UI; } \\
\text { pantot } \\
\text { occidio }\end{array}$ & $\begin{array}{l}00 \mathrm{mg} ; \mathrm{I}-2 \\
00 \mathrm{mg} ; \mathrm{Vi} \\
00 \mathrm{mg} ; \mathrm{C} \\
00.000 \mathrm{n}\end{array}$ & $\begin{array}{l}\text { mg; Veículo } \\
400 \text { mg; Vit. } \\
\text {-52.000 mg; } \\
\text { Promotor de }\end{array}$ \\
\hline
\end{tabular}

em que: $Y_{i j}=$ valor observado das variáveis estudadas relativos à unidade experimental $\mathrm{j}$, recebendo o nível de substituição i de farelo de canola; $\mu=$ média geral; $\mathrm{N}_{\mathrm{i}}=$ efeito do nível de inclusão de farelo de canola i, sendo i $=10,20,30$ e $40 \%$; $\mathrm{e}_{\mathrm{ij}}=$ erro aleatório associado a cada observação $\mathrm{Y}_{\mathrm{ij}}$. Os graus de liberdade referentes aos níveis de substituição, excluindo a ração testemunha, foram 
desdobrados em polinômios.

Para comparação dos resultados obtidos durante a fase inicial entre a ração testemunha com cada um dos níveis de substituição do farelo de canola testados, foi utilizado o teste de Dunnett a 5\% de significância.

\section{Resultados e Discussão}

Os resultados de desempenho referentes ao período inicial estão apresentados na Tabela 2.

Aos 21 dias, excluindo a testemunha, pela análise de regressão, observou-se decréscimo linear no consumo de ração ( $\left.\mathrm{Y}=1242,11-10,5913 \mathrm{X} ; \mathrm{r}^{2}=0,98\right)$, peso médio ( $\left.\mathrm{Y}=942,898-8,82939 \mathrm{X} ; \mathrm{r}^{2}=0,98\right)$ e ganho de peso ( $\left.Y=897,341-8,83042 \mathrm{X} ; \mathrm{r}^{2}=0,98\right)$, bem como piora na conversão alimentar $(Y=1,3661+0,00335928 X$; $\mathrm{r}^{2}=0,79$ ), à medida que aumentavam os níveis de inclusão de farelo de canola.

O teste de Dunnett mostrou redução $(\mathrm{P}<0,05)$ de $10,93,21,65$ e $29,94 \%$ no consumo de ração para as aves alimentadas com 20, 30 e $40 \%$ de farelo de canola, respectivamente, quando comparados à testemunha, provavelmente devido ao sabor adstringente do tanino contido no farelo, o que tornaria as aves mais seletivas aos maiores níveis de inclusão. Estes dados contrariam os de Leeson et al. (1987), que não obtiveram diferenças no consumo quando substituíram totalmente o farelo de soja pelo farelo de canola.

Para a característica peso médio, através do teste de Dunnett, observa-se redução $(\mathrm{P}<0,05)$ de 11,45 a 32,55\% em relação à testemunha, quando se utiliza de 20 a $40 \%$ de farelo de canola na ração, respectivamente, certamente devido aos valores di- minuídos de consumo de ração e, conseqüentemente, de ganho de peso. Estes resultados contrariam Hulan \& Proudfoot (1981), que afirmaram ser possível a utilização de até $80 \%$ de farelo de canola para frangos de corte de 1 a 27 dias de idade, sem prejuízos no peso vivo dos animais. Blair et al. (1986) utilizando diferentes variedades de farelo de canola em níveis de $20 \%$ de inclusão não encontraram efeitos para as variáveis peso vivo, consumo e eficiência alimentar durante o período de 14 a 28 dias, coincidindo com os resultados relatados no presente trabalho.

Houve prejuízo $(\mathrm{P}<0,05)$ de 12,06 a 34,31\% no ganho de peso, quando comparados à testemunha, ao se utilizar de 20 a $40 \%$ de farelo de canola na ração inicial de frangos de corte, respectivamente, estando tal resultado de acordo com Franzoi et al. (1998) e Kocher et al. (2000). A redução observada no ganho de peso pode ser conseqüência do menor consumo de ração, bem como pelo alto teor de fibra bruta encontrado no farelo (15,52\%), quase três vezes a quantidade encontrada no farelo de soja (5,92\%), o que levaria à redução na digestibilidade dos nutrientes, principalmente de proteína (Nascimento, 1997). Elkin et al. (1991) observaram que frangos de corte alimentados com sorgo com alto teor de tanino apresentaram depressão no crescimento e atribuem este fato aos efeitos tóxicos e ações prejudiciais específicas de taninos condensados, incluindo a ligação de proteína no intestino, prejudicando, primariamente, a utilização do alimento pelo animal.

A conversão alimentar apresentou piora $(\mathrm{P}<0,05)$ apenas para os níveis de inclusão de 30 e $40 \%$, pelo teste de Dunnett. Resultados semelhantes foram obtidos por Summers et al. (1992) que não encontra-

Tabela 2 - Desempenho de frangos de corte durante o período inicial submetidos a rações contendo diferentes níveis de farelo de canola

Table 2 - Performance of broiler chickens on starting period fed on diets containing different levels of canola meal

\begin{tabular}{|c|c|c|c|c|c|c|c|}
\hline \multirow[t]{2}{*}{$\begin{array}{l}\text { Variáveis } \\
\text { Parameters }\end{array}$} & \multicolumn{5}{|c|}{$\begin{array}{l}\text { Níveis de inclusão de farelo de canola (\%) } \\
\text { Inclusion levels of canola meal }\end{array}$} & \multirow[t]{2}{*}{$\mathrm{CV}(\%)$} & \multirow[t]{2}{*}{$\begin{array}{l}\text { Regressão } \\
\text { Regression }\end{array}$} \\
\hline & 00 & 10 & 20 & 30 & 40 & & \\
\hline $\begin{array}{l}\text { Consumo de ração(g) }{ }^{1} \\
\text { Feed intake }\end{array}$ & 1169,92 & 1130,90 & $1042,10^{*}$ & $916,64^{*}$ & $819,68 *$ & 1,91 & $Y=1242,11-10,5913 X ; r^{2}=0,98$ \\
\hline $\begin{array}{l}\text { Peso médio (g) }{ }^{1} \\
\text { Body weight }\end{array}$ & 872,30 & 850,89 & $772,45 *$ & $676,88 *$ & $588,43^{*}$ & 2,00 & $Y=942,898-8,82939 X ; r^{2}=0,98$ \\
\hline $\begin{array}{l}\text { Ganho de peso }(\mathrm{g})^{1} \\
\text { Weight gain }\end{array}$ & 826,44 & 805,37 & $726,78^{*}$ & $631,28 *$ & $542,88 *$ & 2,09 & $Y=897,341-8,83042 X ; r^{2}=0,98$ \\
\hline $\begin{array}{l}\text { Conversão alimentar }(\mathrm{g} / \mathrm{g})^{1} \\
\text { Feed conversion }\end{array}$ & 1,416 & 1,404 & 1,434 & $1,452^{*}$ & $1,510^{*}$ & 1,29 & $Y=1,3661+0,00335928 X ; r^{2}=0,79$ \\
\hline
\end{tabular}


ram restrições quanto ao uso de $25 \%$ de farelo de canola, suplementado ou não com enxofre, nas rações para frangos de corte em período inicial.

Jansman (1993) afirmou que os taninos podem reduzir o ganho de peso e a digestibilidade aparente de nitrogênio, aminoácidos e, em menor extensão, energia, para não-ruminantes em crescimento, além de prejudicar a eficiência de conversão dos alimentos. Entretanto, as informações contidas na literatura são conflitantes em relação à influência dos taninos sobre o consumo.

Os resultados médios de desempenho das aves durante o período de 21 a 41 dias de idade referente a ganho de peso, peso médio, consumo de ração e conversão alimentar estão apresentados na Tabela 3.

As características peso médio ( $\mathrm{Y}=2512,60$ $\left.10,8017 X ; r^{2}=0,93\right)$ e ganho de peso ( $Y=1583,54$ $\left.3,46803 X ; r^{2}=0,59\right)$ foram influenciadas negativamente $(\mathrm{P}<0,05)$ durante o período de crescimento pela utilização do farelo de canola no período de 1 a 21 dias. Para a variável peso médio houve redução $(P<0,05)$ de 47,76, 144,53, 297,97 e 400,68 g, para os níveis de inclusão de farelo de canola de 10, 20, 30 e 40\%, respectivamente, em relação ao peso apresentado pelos animais alimentados com a ração testemunha.

Esta diminuição no peso médio das aves pode ser explicada pelo decréscimo observado na variável ganho de peso, em que as aves alimentadas com os níveis de 10, 20, 30 e 40\% de farelo de canola apresentaram -23,51, -20,98, -77,21 e -129,29 g de ganho de peso, respectivamente, durante o período de crescimento, quando comparadas à testemunha. Outro fator que poderia ter contribuído para tal prejuízo seria que as aves submetidas a níveis maiores de farelo de canola até os 21 dias de idade iniciaram o período de crescimento com pesos bastante estratificados, não tendo sido possível sua recuperação total. Não se verificou diferença $(P<0,05)$ para consumo de ração e conversão alimentar, sendo provavelmente estes fatores os responsáveis pela recuperação parcial de peso observada.

Observou-se que, apesar do decréscimo linear, a utilização de níveis de 10 e $20 \%$ de farelo de canola na fase inicial apresentou valores bastante semelhantes ao obtido pela testemunha aos 41 dias de idade.

Quando fornecido em níveis superiores a 30\%, o farelo de canola causou prejuízos no desempenho sem possibilidades de recuperação em tempo hábil, podendo-se atribuir este fato à ação dos taninos e ao alto teor de fibra bruta do alimento em questão.

Os resultados de morfometria do epitélio intestinal aos 21 dias de idade estão apresentados na Tabela 4.

Houve aumento linear $(\mathrm{P}<0,05)$ na profundidade de cripta ( $\mathrm{Y}=236,522+0,922922 \mathrm{X} ; \mathrm{r} 2=0,94)$ para os maiores níveis de inclusão de farelo de canola. Este fato pode ser atribuído à ação dos taninos sobre o revestimento interno da mucosa, tendo sido observados efeitos como descamação do epitélio esofagiano, espessamento do papo, necrose das mucosas gástrica e duodenal e erosão superficial da mucosa; efeitos estes que podem reduzir a capacidade absortiva do trato gastrintestinal, contribuindo para uma piora no desempenho animal (Nyachoti et al., 1997).

Jansman (1993) afirmou que determinados tipos de taninos exercem efeitos significantes na morfologia da parede intestinal e no metabolismo e, conseqüentemente, na absorção de nutrientes. Os taninos possuem a propriedade de se ligar a moléculas de carboidratos e principalmente de proteínas, ficando o grau de afinidade entre ambos determinado pela natureza dos mesmos.

Parte do processo de digestão acontece no duodeno por ação das enzimas provenientes do pâncreas exócrino. A degradação final de proteínas e carboidratos ocorre em nível das microvilosidades, nas quais as peptidases e dissacaridases, aderidas ao glicocálix, liberam aminoácidos e monossacarídeos. Tais monômeros são transportados através das células por ação de proteínas transportadoras específicas (Gartner \& Hiatt, 1997). Deste modo, devido à capacidade dos taninos de se ligarem às proteínas provenientes do alimento, indisponibilizando-as para utilização como nutriente, pode ocorrer ainda a ligação do mesmo às proteínas responsáveis pelo transporte de substâncias para a célula, impedindo a degradação de nutrientes em nível celular.

O muco é uma glicoproteína (mucina) insolúvel em água, secretada pelas células caliciformes, funciona como protetor do epitélio intestinal, impede o contato de microorganismos, secreções do próprio organismo com a mucosa e ações mecânicas. (Macari \& Maiorka, 2000). Assim, os taninos podem ter se ligado ao muco produzido pelas células caliciformes, induzindo a uma secreção maior como compensação, levando ao aumento na profundidade da 
cripta (Figura 1), a fim de suprir tal deficiência, com o aumento de produção de células-tronco indiferenciadas, as quais se diferenciarão em células caliciformes ou absortivas durante o processo de ascensão.

Não se verificaram diferenças $(\mathrm{P}>0,05)$ para as variáveis altura de vilo e relação vilo:cripta, acrescentando-se que a integridade das vilosidades não foi prejudicada.

Assim, a inclusão de farelo de canola nas rações para frangos de corte no período inicial levou a um aumento na profundidade de cripta sem, no entanto, afetar os parâmetros altura de vilo e relação vilo:cripta.

Tabela 3 - Desempenho de frangos de corte durante o período de crescimento submetidos a rações contendo diferentes níveis de farelo de canola durante o período inicial

Table 3 - Performance of broiler chickens on growing period fed on diets containing different levels of canola meal during starting period

\begin{tabular}{|c|c|c|c|c|c|c|c|}
\hline \multirow[t]{2}{*}{$\begin{array}{l}\text { Variáveis } \\
\text { Parameters }\end{array}$} & \multicolumn{5}{|c|}{$\begin{array}{l}\text { Níveis de inclusão de farelo de canola (\%) } \\
\text { Inclusion levels of canola meal }\end{array}$} & \multirow[t]{2}{*}{ CV (\%) } & \multirow[t]{2}{*}{$\begin{array}{l}\text { Regressão } \\
\text { Regression }\end{array}$} \\
\hline & 00 & 10 & 20 & 30 & 40 & & \\
\hline $\begin{array}{l}\text { Consumo de ração (g) } \\
\text { Feed intake }\end{array}$ & 3341,37 & 3467,97 & 3503,06 & 3280,23 & 3263,73 & 6,17 & ns \\
\hline $\begin{array}{l}\text { Peso médio }(\mathrm{g})^{1} \\
\text { Body weight }\end{array}$ & 2474,85 & 2427,06 & 2330,30 & 2176,80 & 2074,50 & 1,94 & $\mathrm{Y}=2512,60-10,8017 \mathrm{X} ; \mathrm{r}^{2}=0,93$ \\
\hline $\begin{array}{l}\text { Ganho de peso }(\mathrm{g})^{1} \\
\text { Weight gain }\end{array}$ & 1569,11 & 1544,35 & 1546,98 & 1487,76 & 1432,81 & 2,97 & $Y=1583,54-3,46803 X ; r^{2}=0,59$ \\
\hline $\begin{array}{l}\text { Conversão alimentar (g/g) } \\
\text { Feed conversion }\end{array}$ & 2,129 & 2,256 & 2,265 & 2,205 & 2,278 & 7,77 & $\mathrm{~ns}$ \\
\hline
\end{tabular}

${ }^{1}(\mathrm{P}<0,05)$.

Tabela 4 - Morfometria de epitélio intestinal (duodeno) de frangos de corte aos 21 dias de idade submetidos a rações contendo diferentes níveis de farelo de canola

Table 4 - Intestinal epithelium (duodenum) morphometry of 21 days broiler chickens fed on rations containing different levels of canola meal

\begin{tabular}{|c|c|c|c|c|c|c|c|}
\hline \multirow[t]{2}{*}{$\begin{array}{l}\text { Variáveis } \\
\text { Parameters }\end{array}$} & \multicolumn{5}{|c|}{$\begin{array}{c}\text { Níveis de inclusão de farelo de canola (\%) } \\
\text { Inclusion levels of canola meal }\end{array}$} & \multirow[t]{2}{*}{ CV (\%) } & \multirow[t]{2}{*}{$\begin{array}{l}\text { Regressão } \\
\text { Regression }\end{array}$} \\
\hline & 0 & 10 & 20 & 30 & 40 & & \\
\hline $\begin{array}{l}\text { Altura de vilo }(\mu \mathrm{m}) \\
\text { Villus height }\end{array}$ & 1444,250 & 1452,687 & 1644,115 & 1517,601 & 1348,206 & 9,822 & ns \\
\hline $\begin{array}{l}\text { Prof. de cripta }(\mu \mathrm{m})^{1} \\
\text { Crypt depth }\end{array}$ & 239,777 & 235,071 & 266,013 & 261,165 & 272,876 & 14,515 & $Y=236,522+0,922922 X ; r^{2}=0,94$ \\
\hline $\begin{array}{l}\text { Relação vilo:cripta } \\
\text { Villus:crypt ratio }\end{array}$ & 6,123 & 6,339 & 6,253 & 6,013 & 5,130 & 14,177 & ns \\
\hline
\end{tabular}

$1(\mathrm{P}<0,05)$. 

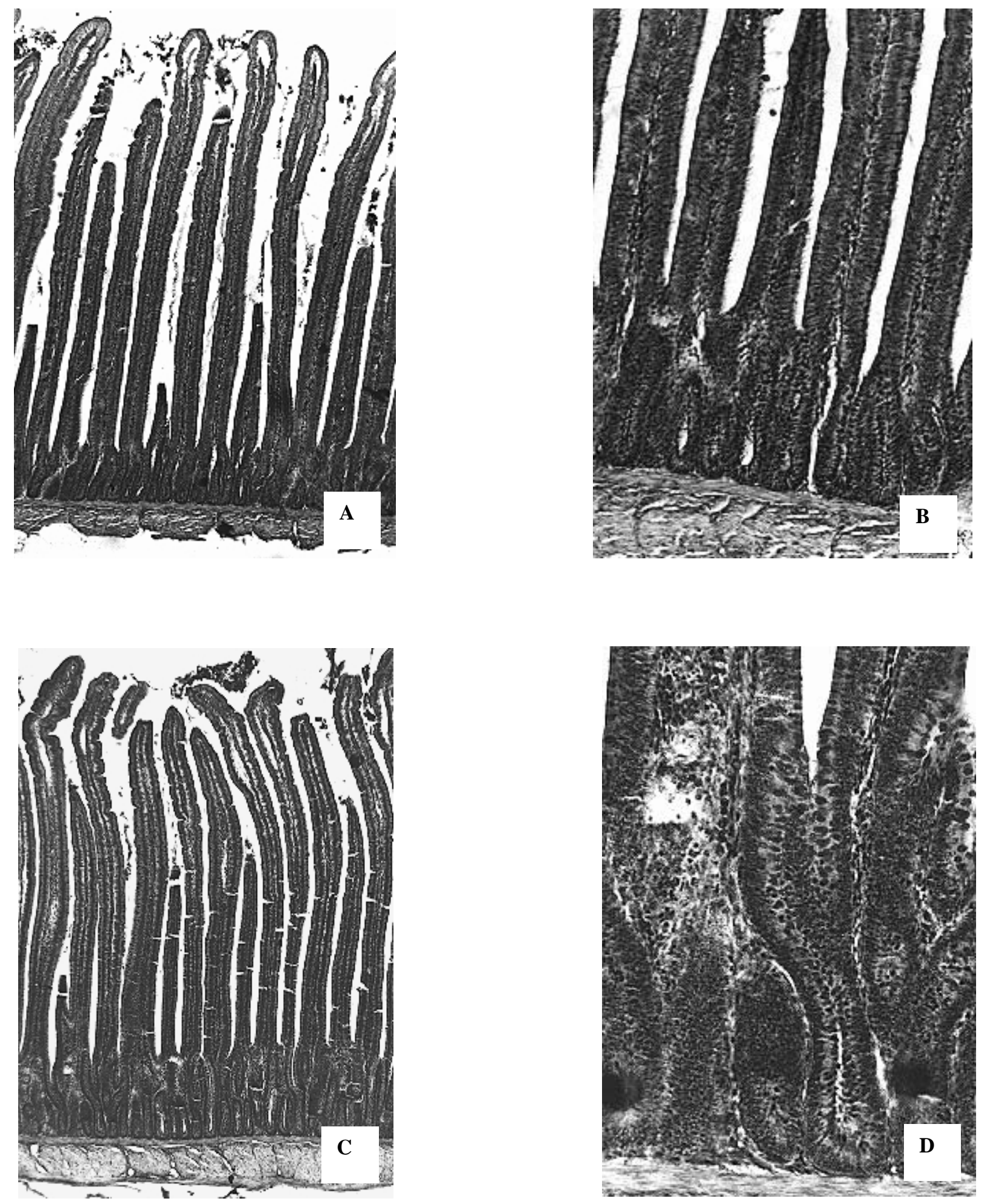

A. Duodeno de aves alimentadas com $10 \%$ de farelo de canola. 60 X. B. Detalhe de criptas do duodeno de aves alimentadas com $10 \%$ de farelo de canola. 151 X. C. Duodeno de aves alimentadas com $40 \%$ de farelo de canola. 60 X. D. Detalhe de criptas do duodeno de aves alimentadas com $40 \%$ de farelo de canola. $306 \mathrm{X}$.

Figura 1 - Fotomicrografias de cortes longitudinais de $5 \mu \mathrm{m}$ de espessura do duodeno de aves alimentadas com níveis crescentes de farelo de canola, aos 21 dias de idade. Coloração PAS.

Figure 1 - Photomicrographies of duodenum longitudinal cuts of $5 \mu \mathrm{m}$ of thickness of birds fed with growing levels of canola meal, at 21 days of age. PAS staining.

R. Bras. Zootec., v.32, n.6, p.1321-1329, 2003 


\section{Conclusões}

De acordo com os resultados de desempenho obtidos aos 21 e 41 dias de idade de aves alimentadas com níveis crescentes de farelo de canola, determinou-se que a utilização de até $20 \%$ de farelo de canola em rações iniciais para frangos de corte induz a resultados satisfatórios para ambas as fases, baseados nos resultados de conversão alimentar para este período. A decisão em substituir o farelo de soja pelo farelo de canola fica em função do preço e da disponibilidade do produto.

A utilização do farelo de canola induziu a aumento na profundidade de cripta, provavelmente devido à ligação do tanino ao muco produzido, bem como às proteínas transportadoras da célula absortiva, criando a necessidade de produção de células-tronco indiferenciadas para suprir a deficiência resultante.

\section{Literatura Citada}

BELL, J.M. Factors affecting the nutritional value of canola meal: a review. Canadian Journal of Animal Science, v.73, n.4, p.679-697, 1993.

BLAIR, R.; MISIR, R.; BELL, J.M. et al. The chemical composition and nutritional value for chickens of meal from recent cultivars of canola. Canadian Journal of Animal Science, v.66, n.3, p.821-825, 1986.

ELKIN, R.G.; ROGLER, J.C.; SULLIVAN, T.W. Differential response of ducks and chicks to dietary sorghum tannins. Journal of the Science of Food and Agriculture, v.57, p.543-553, 1991.

FRANZOI, E.E.; SIEWERDT, F.; RUTZ, F. et al. Desempenho de frangos de corte alimentados com diferentes níveis de farelo de canola. Ciência Rural, v.28, n.4, p.683-689, 1998.

FRANZOI, E.E.; SIEWERDT, F.; RUTZ, F. et al. Composição de carcaça de frangos de corte alimentados com farelo de canola. Ciência Rural, v.30, n.2, p.337-342, 2000.

GARTNER, L.P.; HIATT, J.L. Histología. Texto y atlas. 1.ed. Ciudad de Mexico: McGraw-Hill, 1997. 506p.

HULAN, H.W.; PROUDFOOT, F.G. Replacement of soybean meal in chicken broiler diets by rapeseed meal and fish meal complementary sources of dietary protein. Canadian Journal of Animal Science, v.61, n.4, p.999-1004, 1981.

JANSMAN, A.J.M. Tannins in feedstuffs for simple-stomached animals. Nutrition Research Reviews, n.6, p.209-236, 1993.

KOCHER, A.; CHOCT, M.; PORTER, M.D. et al. The effects of enzyme addition to broiler diets containing high concentrations of canola or sunflower meal. Poultry Science, v.79, n.12, p.1767-1774, 2000.
LEESON, S.; SLINGER, S.J.; SUMMERS, J.D. Utilization of whole Tower rapeseed by laying hens and broiler chickens. Canadian Journal of Animal Science, v.58, n.1, p.55-61, 1978.

LEESON, S.; ATTEH, J.O.; SUMMERS, J.D. The replacement value of canola meal for soybean meal in poultry diets. Canadian Journal of Animal Science, v.67, n.1, p.151158, 1987.

MACARI, M.; MAIORKA, A. Função gastrintestinal e seu impacto na produção avícola. In: CONFERÊNCIA APINCO DE CIÊNCIA E TECNOLOGIA AVÍCOLAS, 2000, Campinas. Anais ... Campinas: APINCO, 2000. p.161-174.

MITARU, B.N.; BLAIR, R.; BELL, J.M. et al. Effect of canola hulls on growth, feed efficiency, and protein and energy utilization in broiler chickens. Canadian Journal of Animal Science, v.63, n.3, p.655-662, 1983.

MURAKAMI, A.E.; KIRA, K.C.; SCAPINELLO, C. et al. Farelo de canola na alimentação de poedeiras comerciais. Revista da Sociedade Brasileira de Zootecnia, v.24, n.3, p.401-408, 1995a.

MURAKAMI, A.E.; OKAMOTO, E.; MOREIRA, I. et al. Farelo de canola na alimentação de frangos de corte. Revista da Sociedade Brasileira de Zootecnia, v.24, n.3, p.437444, 1995b.

NASCIMENTO, A.H. Avaliação química e energética do farelo de canola e sua utilização para frangos de corte. Viçosa, MG: Universidade Federal de Viçosa, 1997. 59p. Dissertação (Mestrado em Zootecnia) - Universidade Federal de Viçosa, 1997.

NERILO, N. Disponibilidade de metionina e cistina da semente e do farelo de canola. Maringá: Universidade Estadual de Maringá, 1995. 33p. Dissertação (Mestrado em Zootecnia) - Universidade Estadual de Maringá, 1995.

NYACHOTI, C.M.; ATKINSON, J.L.; LEESON, S. Sorghum tannins: a review. World's Poultry Science Journal, v.53, p.5-21, 1997.

POUR-REZA, J.; EDRISS, M.A. Effects of dietary sorghum of different tannin concentrations and tallow supplementation on the performance of broiler chicks. British Poultry Science, v.38, p.512-517, 1997.

ROSTAGNO, H.S.; ALBINO, L.F.T.; DONZELE, J.L. et al. Tabelas Brasileiras para Aves e Suínos - Composição de Alimentos e Exigências Nutricionais. Viçosa, MG: Universidade Federal de Viçosa, 2000. 141p.

SUMMERS, J.D.; SPRATT, D.; BEDFORD, M. Sulphur and calcium supplementation of soybean and canola meal diets. Canadian Journal of Animal Science, v.72, n.1, p.127-133, 1992. 